\title{
Short term guide-line prices in pig meat market
}

\author{
A. VIGNE *, P. MAINSANT **, M. RIEU *, Guillemette MICHOULIER ** \\ *I.T.P., 34, boulevard de la Gare, 31500 Toulouse \\ ** I.N.R.A., Laboratoire de Recherches et d'Etudes sur l'Economie \\ des Industries agricoles et alimentaires, 3, rue du Caducée, B.P. 333, \\ 94153 Rungis Cedex \\ France
}

The different ruling prices in pig meat market (carcasses and cuts in France and in the E.E.C.) are interrelated.

Seen at a very short term through the weekly price series, this mechanism is not always instantaneous : lags are frequent between price variations. Certain "guide-line» prices are detected, the variations of which are transmitted to other prices with a more or less important lag. The method of cross-correlations over lagged weekly variations was used.

Two different guide-line prices were revealed by this study: auction prices in the Brittany market (Cadran) and to a less extent the national quotation of pork in West Germany.

Importing countries generally seem to anticipate the short term price fluctuations of the exporting countries. The study shows the importance of real import-export transaction prices in transmitting guide-line price influences.

These general conclusions are subject to a few exceptions, in particular the apparent independency of the Italian market.

\author{
Prices in the pig channel \\ M. RIEU, A. VIGNE \\ I.T.P., 34, boulevard de la Gare, 31500 Toulouse \\ France
}

Variations in the different prices of the French pig channel (1970-1981) from production to retail distribution were compared.

Various divergencies were noted. Retail prices increase more rapidly than production prices $(9.4$ p. 100 against 6.3 p. 100). The increase at the intermediate levels lies between these two figures.

The distribution of margin increases over the whole pig production sector differs according to products. The overall pig channel includes three different branches : fresh meat, salted or cured processed pork products and ham.

The branch of salted or cured processed meat products has the highest purchase margin improvement, followed by the retail distribution of fresh meat and processed pork products.

On the other hand, the slaughtering and cutting branch which is also highly industrialized has some difficulties in improving its margin.

Differences in working expenses can to a certain extent explain these differences in the price behaviour. It could also be explained by the structural differences and the harder competition prevailing in the slaughtering branch.

The output of the pig channel has a regulatory impact on the fluctuations of pig meat prices, nevertheless, these fluctuations remain perceptible at the retail distribution level. 